\title{
Cardiogenic Shock \& Machine Learning: A Systematic Review on Prediction Through Clinical Decision Support Softwares
}

\author{
Rene Aleman ${ }^{1}$, Sinal Patel ${ }^{1}$, Jose Sleiman ${ }^{1}$, Jose Navia ${ }^{2}$, Cedric Sheffield ${ }^{1}$, and Nicolas \\ Brozzi ${ }^{3}$ \\ ${ }^{1}$ Cleveland Clinic Florida \\ ${ }^{2}$ Cleveland Clinic \\ ${ }^{3}$ Cleveland Clinic Foundation
}

August 3, 2021

\begin{abstract}
Background \& Aim Cardiogenic shock (CS) withholds a significantly high mortality rate between 40-60\% despite advances in diagnosis and medical/surgical intervention. To-date, machine learning(ML) is being implemented to integrate numerous data to optimize early diagnostic predictions and suggest clinical courses. This systematic review summarizes the area under the curve (AUC) receiver operating characteristics (ROC) accuracy for the early prediction of CS. Methods A systematic review was conducted within databases of PubMed, ScienceDirect, Clinical Key/MEDLINE, Embase, GoogleScholar, and Cochrane. Cohort studies that assessed accuracy of early detection of CS using ML software were included. Data extraction was focused on AUC-ROC values directed towards early detection of CS. Results A total of 943 studies were included for systematic review. From the reviewed studies, $2.2 \%(\mathrm{~N}=21)$ evaluated patient outcomes, of which $14.3 \%(\mathrm{~N}=3)$ were assessed. The collective patient cohort $(\mathrm{N}=698)$ consisted of $314(45.0 \%)$ females, with an average age and body mass index (BMI) of 64.1 years and $28.1 \mathrm{~kg} / \mathrm{m} 2$, respectively. Collectively, $159(22.8 \%)$ mortalities were reported following early CS detection. Altogether, the AUCROC value was $0.82(\mathrm{alfa}=0.05)$, deeming it of superb sensitivity and specificity. Conclusions From the present comprehensively gathered data, this study accounts the use of ML software for the early detection of CS in a clinical setting as a valid tool to predict patients at risk of CS. The complexity of ML and its parallel lack of clinical evidence implies that further prospective randomized control trials are needed to draw definitive conclusions prior to standardizing use of these technologies.
\end{abstract}

Running title: Cardiogenic Shock \& Machine Learning

Rene Aleman $\mathrm{MD}^{1}$ Sinal Patel MD ${ }^{1}$

Jose Sleiman $\mathrm{MD}^{2}$

Jose Navia $\mathrm{MD}^{1}$

Cedric Sheffield MD ${ }^{1}$

Nicolas A. Brozzi MD, FACC ${ }^{1}$

${ }^{1}$ Heart, Vascular \& Thoracic Institute. ${ }^{2}$ Department of Cardiology.

Cleveland Clinic Florida

Corresponding Author

Nicolas A. Brozzi MD, FACC 
Cardiothoracic Surgeon Surgical Director, Mechanical Circulatory Support Program Director of Cardiovascular Research

Heart, Vascular \& Thoracic Institute

Cleveland Clinic Florida

2950 Cleveland Clinic Blvd, Weston FL 33331

BROZZIN@CCF.ORG

+1 (954) 405-4851

Authors contact emails :

ALEMANR2@CCF.ORG

PATELS51@CCF.ORG

\section{SLEIMAJ2@CCF.ORG NAVIAJ@CCF.ORG SHEFFIC@CCF.ORG BROZZIN@CCF.ORG}

No funding was provided for the present manuscript. No acknowledgments.

Ethical statement: the authors are accountable for all aspects of the work in ensuring that questions related to the accuracy or integrity of any part of the work are appropriately investigated and resolved

Author contribution:

1. Concept and design: Rene Aleman

2. Administrative support: Nicolas Brozzi, Cedric Sheffield, and Jose Navia

3. Provision of study materials/patients: Rene Aleman, Jose Sleiman, and Sinal Patel

4. Data analysis and interpretation: Rene Aleman

5. Collection and assembly of data: Rene Aleman and Jose Sleiman

6. Manuscript writing: All authors

7. Final approval of manuscript: Nicolas Brozzi, Cedric Sheffield, and Jose Navia

\section{Hosted file}

ML \& CS_BRIEF SUMMARY \& HIGHLIGHTS.docx available at https://authorea.com/users/428882/ articles/532677-cardiogenic-shock-machine-learning-a-systematic-review-on-predictionthrough-clinical-decision-support-softwares

\section{Hosted file}

ML \& CS_ABSTRACT.docx available at https://authorea.com/users/428882/articles/532677cardiogenic-shock-machine-learning-a-systematic-review-on-prediction-through-clinicaldecision-support-softwares

\section{Hosted file}

ML \& CS_MANUSCRIPT.docx available at https://authorea.com/users/428882/articles/532677cardiogenic-shock-machine-learning-a-systematic-review-on-prediction-through-clinicaldecision-support-softwares

\section{Hosted file}

ML \& CS_TABLES \& FIGURES.docx available at https://authorea.com/users/428882/articles/532677cardiogenic-shock-machine-learning-a-systematic-review-on-prediction-through-clinicaldecision-support-softwares 